\title{
Lipoquinones in Members of the Family Pasteurellaceae
}

\author{
R. M. KROPPENSTEDT ${ }^{1}$ AND W. MANNHEIM ${ }^{2 *}$ \\ Deutsche Sammlung von Mikroorganismen, D-3300 Braunschweig, ${ }^{1}$ and Institut für Medizinische Mikrobiologie, \\ Philipps-Universität, Pilgrimstein 2, D-3550 Marburg, ${ }^{2}$ Federal Republic of Germany
}

\begin{abstract}
Selected members of the family Pasteurellaceae Pohl 1981 were investigated for their lipoquinone contents by using high-performance liquid chromatography. In addition to ubiquinones and demethylmenaquinones, menaquinones (MK-7 or MK-8 or both) were detected, mostly as minor naphthoquinone components, in several Actinobacillus, Pasteurella, and related species. Previous studies that relied on difference spectrophotometry and thin-layer chromatography did not identify menaquinone components in lipid extracts of members of the Pasteurellaceae. The view that this family can be differentiated from the Enterobacteriaceae and other fermenting gram-negative bacteria by a lack of menaquinones cannot be maintained. Although the situation seems to be more complex than previously recognized, the distribution patterns of lipoquinone structural types and their isoprenologs appear to remain a valuable chemotaxonomic tool for these bacteria.
\end{abstract}

Isoprenoid quinones are essential mediators of phosphorylating electron transport in respiring membranes of many procaryotes and eucaryotic organelles. They are associated with respiratory functions and are present in micromolar amounts per gram of cellular protein, with considerable variation depending on environmental conditions $(9,12,14$, $15,19)$. As a rule, aerobic gram-negative chemoorganotrophic eubacteria and mitochondria contain ubiquinones as the sole respiratory quinones involved in aerobic metabolism and nitrate respiration. Facultatively anaerobic and fermentative gram-negative bacteria belonging to ribosomal ribonucleic acid superfamily I sensu De Ley (5) or to the gamma group of the recently proposed class Proteobacteria (27) may be capable of producing respiratory naphthoquinones. The Flavobacterium-Cytophaga group and related taxa, gram-negative strictly anaerobic eubacteria, and aerobic gram-positive eubacteria contain naphthoquinones as sole respiratory quinones $(3,4)$. Menaquinones, methylmenaquinones, and demethylmenaquinones may support phosphorylating electron transport to low-potential acceptors (e.g., fumarate) $(13,16)$. Both the distribution of lipoquinone structural types and the length and degree of saturation of their isoprenoid side chains are of chemotaxonomic interest $(3,4)$.

Previous studies on the respiratory quinones of members of the family Pasteurellaceae Pohl 1979 (6-8, 23) were performed with lipid extracts of wet cell homogenates containing less than $10 \mathrm{mg}$ of bacterial protein $(17,18)$ by using difference spectrophotometry of reduced-minus-oxidized ethanolic solutions and thin-layer chromatography (20). These studies indicated that members of the family Pasteurellaceae produce demethylmenaquinones as the sole respiratory naphthoquinones or demethylmenaquinones and ubiquinones. Several species that produced only menaquinones or only ubiquinones were excluded from the family Pasteurellaceae, and the absence of menaquinones in the naphthoquinone fraction was used as a taxonomic marker to separate this group from other gram-negative organisms belonging to the first and fifth ribosomal ribonucleic acid superfamilies $(7,22)$. More recently, however, the development of improved analytical methods, e.g., high-performance liquid chromatography (HPLC), have allowed more refined separation of quinone mixtures (3). Recently, Car-

\footnotetext{
* Corresponding author.
}

lone et al. (2) reported the presence of both menaquinones and demethylmenaquinones in Haemophilus ducreyi and questioned the inclusion of this species in the family Pasteurellaceae.

In this paper we present evidence that by performing HPLC analyses of samples containing at least $100 \mathrm{mg}$ of bacterial dry mass, menaquinones can be detected, mostly as minor components, in addition to demethylmenaquinones and ubiquinones, in selected strains representing well-established groups of the Pasteurellaceae. Moreover, our data contain additional information on the distribution patterns of quinone isoprenologs in this family.

\section{MATERIALS AND METHODS}

Microorganisms. Selected type or reference strains of species covering the whole range of phylogenetic diversity in the family Pasteurellaceae (Table 1) were grown from the lyophilized state on chocolate agar, cloned by subculturing typical single colonies, and identified by conventional methods (11).

Production of cell mass. Oxygen-limited cultures were grown in 500-ml batches of Proteose Peptone-glucose medium in 2-liter Fernbach flasks which were moderately shaken (gyratory shaker, $80 \mathrm{rpm}$ ) at $36^{\circ} \mathrm{C}$; cells were harvested in the late exponential growth phase, washed in deionized water, and lyophilized. The medium consisted of 2\% (wt/vol) Proteose Peptone no. 3 (Difco Laboratories, Detroit, Mich.), $0.5 \%$ (wt/vol) sodium chloride, $0.2 \%$ (wt/ vol) $\mathrm{D}-(+)$-glucose (separately sterilized), and $0.02 \mathrm{M}$ sodium hydrogen carbonate (sterilized by filtration); the final $\mathrm{pH}$ was 7.2. Anaerobic cultures were grown in 1 -liter batches of Proteose Peptone medium supplemented with $0.05 \mathrm{M}$ disodium fumarate (sterilized by filtration) instead of $\mathrm{NaHCO}_{3}$ in Erlenmeyer flasks incubated statically. Before quinone analysis dried cells were stored at $-25^{\circ} \mathrm{C}$ for up to 2 months.

Extraction, purification, and analysis of isoprenoid quinones. Extraction, purification, and analysis of isoprenoid quinones were performed as previously described (26). To avoid confusion of quinone structural types that exhibited identical retention characteristics during HPLC, the individual quinone peaks were further identified by their ultraviolet (UV) spectra. Each peak was scanned at its apex from 220 to $400 \mathrm{~nm}$ by using a diode array detector (model 1090/1040; Hewlett-Packard Co., Palo Alto, Calif.). Each quinone ex- 
TABLE 1. Lipoquinones of selected members of the Pasteurellaceae as determined by HPLC

\begin{tabular}{|c|c|c|c|c|c|c|c|c|c|}
\hline \multirow{3}{*}{ Species or group } & \multirow{3}{*}{ Strain $^{a}$} & \multirow{3}{*}{$\begin{array}{l}\text { Terminal } \\
\text { electron } \\
\text { acceptor }\end{array}$} & \multicolumn{7}{|c|}{$\%$ of total quinones } \\
\hline & & & \multicolumn{2}{|c|}{ Menaquinones } & \multicolumn{2}{|c|}{$\begin{array}{l}\text { Demethyl- } \\
\text { menaquinones }\end{array}$} & \multicolumn{3}{|c|}{ Ubiquinones } \\
\hline & & & MK-7 & MK-8 & DMK-7 & DMK-8 & Q-6 & Q-7 & Q-8 \\
\hline \multirow[t]{2}{*}{ Pasteurella multocida } & NCTC $10322^{\mathrm{T} b}$ & $\mathrm{O}_{2}$ & & 23.6 & & 30.9 & & & 45.5 \\
\hline & & Fumarate & & 1.0 & & 60.0 & & & 39.0 \\
\hline Pasteurella gallinarum & ATCC $13361^{\mathrm{T}}$ & $\mathrm{O}_{2}$ & 3.0 & 2.0 & & 14.0 & & 22.0 & 59.0 \\
\hline Actinobacillus lignieresii & NCTC $4189^{\mathrm{T}}$ & $\mathrm{O}_{2}$ & 19.0 & 2.0 & 74.0 & 5.0 & & & \\
\hline Actinobacillus equuli & NCTC 3365 & $\mathrm{O}_{2}$ & 28.0 & & 72.0 & & & & \\
\hline \multirow{2}{*}{$\begin{array}{l}\text { Pasteurella pneumotropica biotype } \\
\text { Jawetz }\end{array}$} & NCTC $8141^{\mathrm{T}}$ & $\mathrm{O}_{2}$ & & & 97.9 & 2.3 & & & \\
\hline & & Fumarate & & & 99.8 & 0.2 & & & \\
\hline Pasteurella haemolytica & NCTC $9380^{\mathrm{T}}$ & $\mathrm{O}_{2}$ & 22.4 & & 17.9 & & & & \\
\hline \multirow{4}{*}{$\begin{array}{l}\text { Pasteurella haemolytica biotype } \mathrm{A} \\
\text { Pasteurella haemolytica biotype } \mathrm{T} \\
\text { Haemophilus paragallinarum } \\
\text { Haemophilus influenzae }\end{array}$} & NCTC 10610 & Fumarate & 57.1 & & $\begin{array}{l}18.9 \\
23.0\end{array}$ & & & 24.0 & \\
\hline & NCTC 10624 & $\begin{array}{l}\mathrm{O}_{2} \\
\mathrm{O}_{2}\end{array}$ & $\begin{array}{l}11.0 \\
11.0\end{array}$ & & $\begin{array}{l}23.0 \\
21.0\end{array}$ & & & 68.0 & \\
\hline & NCTC 10926 & Fumarate & 18.0 & 10.0 & & & & 72.0 & \\
\hline & NCTC $8143^{\mathrm{T}}$ & $\mathrm{O}_{2}$ & & & 99.0 & 1.0 & & & \\
\hline \multirow{4}{*}{$\begin{array}{l}\text { Haemophilus parainfluenzae } \\
\text { Haemophilus parahaemolyticus } \\
\text { Haemophilus parasuis } \\
\text { Haemophilus aphrophilus }\end{array}$} & NCTC $7857^{\mathrm{T}}$ & $\mathrm{O}_{2}$ & & & 100.0 & & & & \\
\hline & NCTC $8457^{\mathrm{T}}$ & $\mathrm{O}_{2}$ & & & 100.0 & & & & \\
\hline & NCTC $4557^{\mathrm{T}}$ & $\mathrm{O}_{2}$ & & 4.0 & & & 17.0 & 69.0 & 10.0 \\
\hline & NCTC $5886^{\mathrm{T}}$ & $\mathrm{O}_{2}$ & 1.0 & & 93.0 & 6.0 & & & \\
\hline \multirow{2}{*}{$\begin{array}{l}\text { Actinobacillus actinomycetem- } \\
\text { comitans }\end{array}$} & FDC-Y4 & $\mathrm{O}_{2}$ & & & 96.0 & 4.0 & & & \\
\hline & (HIM 829-8) & Fumarate & & & 97.6 & 2.4 & & & \\
\hline \multirow[t]{2}{*}{ Pasteurella aerogenes } & ATCC $27783^{\mathrm{T}}$ & $\mathrm{O}_{2}$ & & 13.1 & & 8.1 & & & 78.8 \\
\hline & & Fumarate & & 24.2 & & 52.2 & & & 23.6 \\
\hline \multirow[t]{2}{*}{ Bisgaard taxon 14} & HIM 913-2 & $\mathrm{O}_{2}$ & & 8.8 & & 26.5 & & & 64.7 \\
\hline & & Fumarate & & 12.0 & & 76.5 & & & 11.5 \\
\hline
\end{tabular}

${ }^{a}$ ATCC, American Type Culture Collection, Rockville, Md.; HIM, Culture Collection, Department of Medical Microbiology, University of Marburg, Marburg, Federal Republic of Germany; NCTC, National Collection of Type Cultures, Colindale, London, England; FDC, Forsyth Dental Center, Boston, Mass.

${ }^{b} \mathrm{~T}=$ type strain.

hibited specific UV spectrum which could be used for positive identification (Fig. 1 and 2).

\section{RESULTS AND DISCUSSION}

Of the 16 strains of members of the Pasteurellaceae studied, 12 produced menaquinones, mostly as minor com- ponents, in addition to demethylmenaquinones. These organisms represented the genus Pasteurella sensu stricto Mutters et al. 1985 (25), the genus Actinobacillus, the Pasteurella haemolytica complex (24), Haemophilus paragallinarum, Haemophilus parasuis, Haemophilus aphrophilus, Pasteurella aerogenes, and Bisgaard provisional

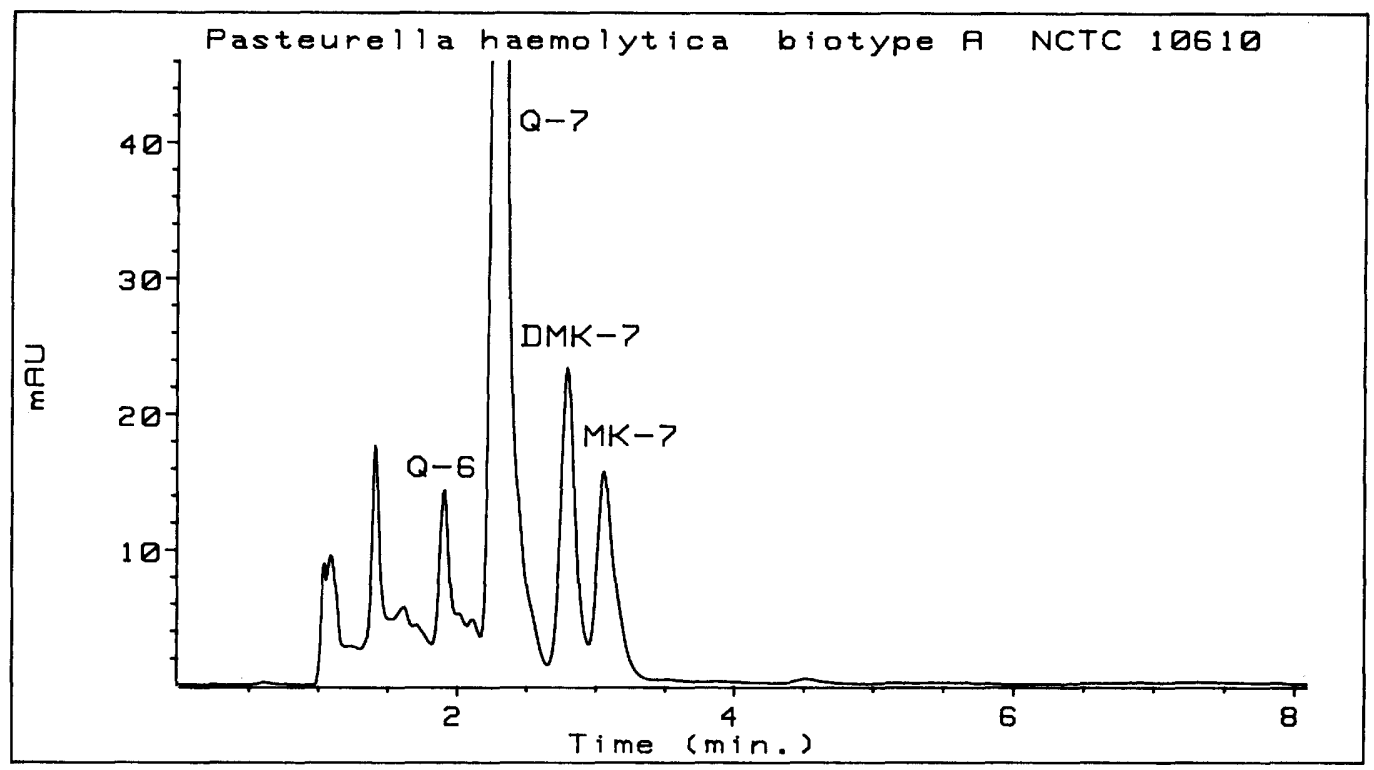

FIG. 1. Separation of Pasteurella haemolytica NCTC 10610 quinones by HPLC. A 100-mg portion of lyophilized cells was extracted twice with $10 \mathrm{ml}$ of chloroform-methanol $(2: 1, \mathrm{vol} / \mathrm{vol})$ for $1 \mathrm{~h}$. A $10-\mu \mathrm{l}$ portion $(5 \%)$ of the reduced filtered extract was used for separation by HPLC. The following conditions were used: ODS column ( 125 by $4 \mathrm{~mm}$ [inside diameter]); particle size, $5 \mu \mathrm{m}$ (Hypersil); column temperature, $40^{\circ} \mathrm{C}$; flow rate, $1 \mathrm{ml} / \mathrm{min}$; eluant, acetonitrile-isopropanol (65:35). mAU, Milliabsorbance units. Q-7, ubiquinone 7 (2,3-dimethoxy-5-methyl3-heptaprenyl-1,4-benzoquinone); MK-7, menaquinone 7 (2-methyl-3-heptaprenyl-1,4-naphthoquinone); DMK-7, demethylmenaquinone 7. 

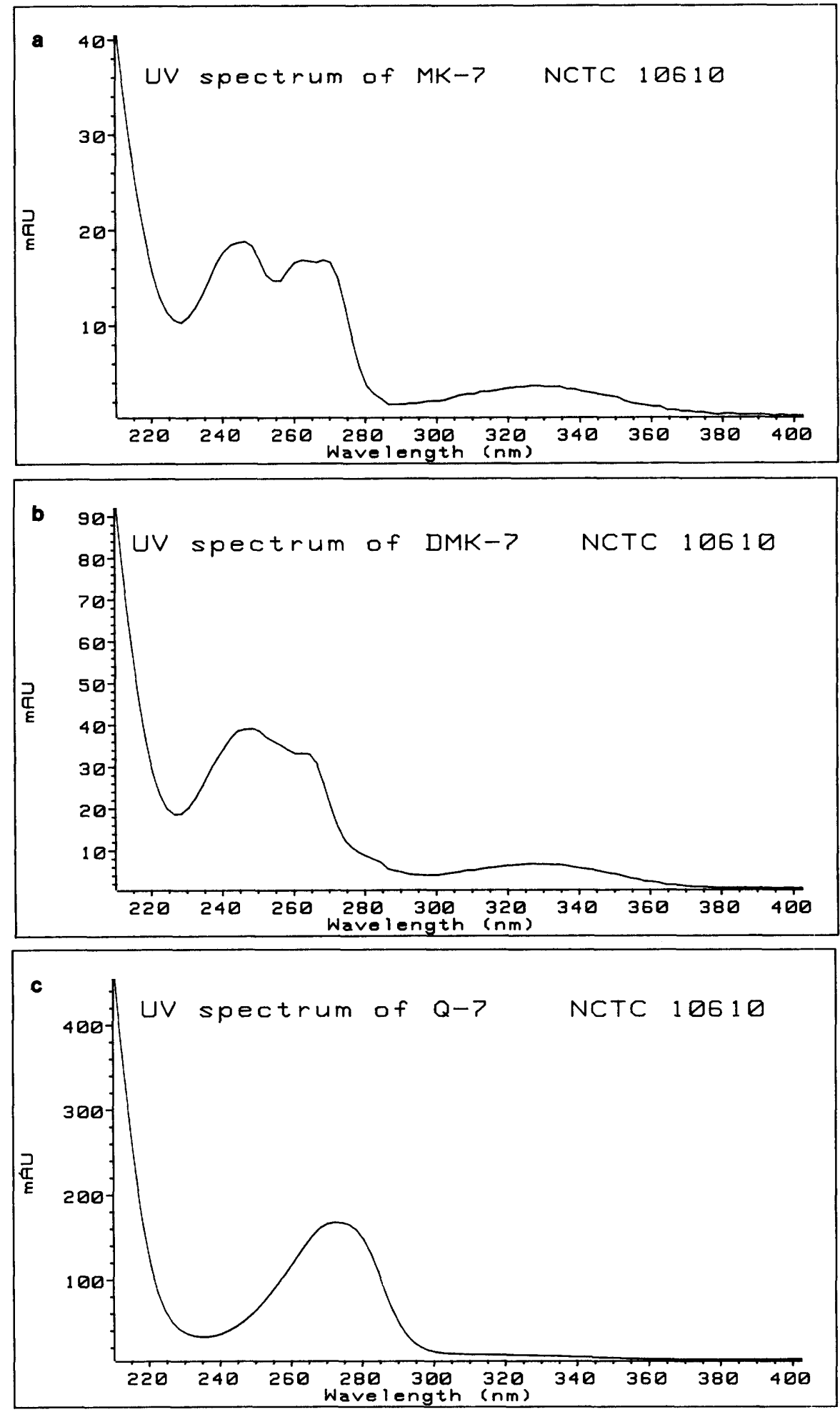

FIG. 2. UV spectra of the separated quinones of Pasteurella haemolytica NCTC 10610. (a) Scanned peak at 3.1. min (MK-7), showing the characteristic UV absorption spectrum of menaquinones. mAU, Milliabsorbance units. (b) Peak at 2.8 min (DMK-7), showing the characteristic UV absorption spectrum of demethylmenaquinones. (c) Peaks at 2.3 and 1.9 min (Q-7), showing the characteristic UV absorption spectrum of ubiquinones.

taxon 14 (1), which has been incorporated in the family Pasteurellaceae on the basis of deoxyribonucleic acid-ribosomal ribonucleic acid hybridization results (U. Rothenpieler, R. Mutters, W. Frederiksen, R. Rossau, P. Segers, J.
De Ley, and W. Mannheim, Abstr. XIV Int. Congr. Microbiol., abstr. no. P.B4-8, 1986). Pasteurella pneumotropica biotype Jawetz, members of the genus Haemophilus sensu stricto (S. Burbach, M.D. thesis, University of Marburg, 
Marburg, Federal Republic of Germany, 1988), and Actinobacillus actinomycetemcomitans did not contain menaquinones, despite the sensitivity of the method; less than $1 \%$ menaquinone is detectable in the total naphthoquinone fraction. Our data also show the dynamics of benzoquinone and naphthoquinone biosynthesis, which depend on the nature of the terminal electron acceptor available during growth (Table 1).

In interpreting the results of the quinone analyses, several aspects of the data should be considered. The production of respiratory quinones has proven to be a rather stable and reliable genetic feature. In the family Pasteurellaceae, the ability to form ubiquinones may be lost in otherwise typical strains of Pasteurella multocida (10) and Actinobacillus equuli (21), whereas a lack of demethylmenaquinone formation has been encountered only once in a collection of more than 300 strains of members of the Pasteurellaceae tested, with strain ATCC 7901 (a misclassified strain that belongs to the Aphrophilus group [21]), which produced an unusual naphthoquinone derivative (8). Phenotypically, on the other hand, the quinone contents of bacteria are considerably influenced by medium composition and culture conditions and vary with the physiological age of the cells examined. Organisms capable of both aerobic respiration and anaerobic respiration, such as the bacterial group considered here, must be studied under both culture conditions to cover the range of variability in their quinone contents.

Analytical procedures may also have influenced previously published data on quinone distribution. If there are different structural quinone types present, the extraction efficiencies should be similar, if not quantitative. With the Kröger extraction procedure, naphthoquinones are quantitatively recovered only in the oxidized state (15). Naphthoquinones are susceptible to degradation under alkaline conditions, in strong light, and in the presence of some oxidants (3). HPLC retention times are highly characteristic for individual quinone types and isoprenologs, but they may coincide (e.g., the retention times for Q-8 and DMK-7); therefore, further identification of the peaks by means of spectrophotometric procedures is required.

The introduction of HPLC has greatly improved the detection of smaller lipoquinone fractions in total lipid extracts. With the present methodology, excellent information on bacterial quinone patterns can be obtained. Even if the taxonomic evaluation of the data becomes more complex, as in the present case, quinone patterns are very useful tools in characterizing species and groups. On the basis of the data presented here, the description of the family Pasteurellaceae must be revised with respect to the capability to produce menaquinones in addition to demethylmenaquinones.

\section{LITERATURE CITED}

1. Bisgaard, M., and R. Mutters. 1986. A new facultatively anaerobic Gram-negative fermentative rod obtained from different pathological lesions in poultry and tentatively designated taxon 14. Avian Pathol. 15:117-127.

2. Carlone, G. M., W. O. Schalla, C. W. Moss, D. L. Ashley, D. M. Fast, J. S. Holler, and B. D. Plikaytis. 1988. Haemophilus ducreyi isoprenoid quinone content and structure determination. Int. J. Syst. Bacteriol. 38:249-253.

3. Collins, M. D. 1985. Analysis of isprenoid quinones, p. 329-366. In G. Gottschalk (ed.), Methods in microbiology, vol. 18 Academic Press, Inc., New York.

4. Collins, M. D., and D. Jones. 1981. Distribution of isoprenoid quinone structural types in bacteria and their taxonomic implications. Microbiol. Rev. 45:316-354.
5. De Ley, J. 1978. Modern molecular methods in bacterial taxonomy: evaluation, application, prospects, p. 247-357. In Proceedings of the 4th International Conference on Plant Pathogenic Bacteria, vol. 1. Gibert-Clarey, Tours, France.

6. Holländer, R. 1976. Correlation of the function of demethylmenaquinone in bacterial electron transport with its redox potential. FEBS Lett. 72:98-100.

7. Holländer, R., A. Hess-Reihse, and W. Mannheim. 1981. Respiratory quinones in Haemophilus, Pasteurella and Actinobacillus, p. 83-97. In M. Kilian, W. Frederiksen, and E. L. Biberstein (ed.), Haemophilus, Pasteurella and Actinobacillus. Academic Press, Inc. (London), Ltd., London.

8. Holländer, R., and W. Mannheim. 1975. Characterization of hemophilic and related bacteria by their respiratory quinones and cytochromes. Int. J. Syst. Bacteriol. 25:102-107.

9. Holländer, R., G. Wolf, and W. Mannheim. 1977. Lipoquinones of some bacteria and mycoplasmas, with considerations on their functional significance. Antonie van Leeuwenhoek J. Microbiol. Serol. 43:177-185.

10. Hoschatt, H., and W. Mannheim. 1979. Zur phänotypischen Charakteristik humaner Pasteurella- und pasteurella-ähnlicher Stämme. Zentralbl. Bakteriol. Mikrobiol. Hyg. A 243:499-510.

11. Kilian, M., and W. Frederiksen. 1981. Identification tables for the Haemophilus-Pasteurella-Actinobacillus group, p. 281-290. In M. Kilian, W. Frederiksen, and E. L. Biberstein (ed.). Haemophilus, Pasteurella and Actinobacillus. Academic Press, Inc. (London), Ltd., London.

12. Kröger, A. 1970. The rate of oxidation of ubiquinone and its position in the respiratory system, p. 145-148. In E. Quagliariello et al. (ed.), Electron transport and energy conservation. Adriatica Editrica, Bari, Italy.

13. Kröger, A. 1974. Electron transport phosphorylation coupled to fumarate reduction in anaerobically grown Proteus rettgeri. Biochim. Biophys. Acta 347:273-289.

14. Kröger, A. 1977. Bakterielle Atmungsketten, p. 17-22. In Biotechnologie, vol. 81. Verlag Chemie, Weinheim, Federal Republic of Germany.

15. Kröger, A. 1978. Determination of contents and redox states of ubiquinone and menaquinone. Methods Enzymol. 53D:579-591.

16. Kröger, A. 1980. Bacterial transport to fumarate, p. 1-17. In C. J. Knowles (ed.), Diversity of bacterial respiratory systems, vol. 2. CRC Press, Inc., Boca Raton, Fla.

17. Kröger, A., and V. Dadák. 1969. On the role of quinones in bacterial electron transport. The respiratory system of Bacillus megaterium. Eur. J. Biochem. 11:328-340.

18. Kröger, A., V. Dadák, M. Klingenberg, and F. Diemer. 1971. On the role of quinones in bacterial electron transport. Differential roles of ubiquinone and menaquinone in Proteus rettgeri. Eur. J. Biochem. 21:322-333.

19. Kröger, A., and G. Unden. 1985. The function of menaquinone in bacterial electron transport, p. 285-300. In G. Lenaz (ed.), Coenzyme Q. John Wiley \& Sons, Ltd., Chichester, United Kingdom.

20. Mannheim, W. 1981. Taxonomically useful test procedures pertaining to bacterial lipoquinones and associated functions, with special reference to Flavobacterium and Cytophaga, p. 114-125. In H. Reichenbach and O. B. Weeks (ed.), The Flavobacterium-Cytophaga group. Verlag Chemie, Weinheim, Federal Republic of Germany.

21. Mannheim, W. 1981. Taxonomic implications of DNA relatedness and quinone patterns in Actinobacillus, Haemophilus and Pasteurella, p. 265-280. In M. Kilian, W. Frederiksen, and E. L. Biberstein (ed.), Haemophilus, Pasteurella and Actinobacillus. Academic Press, Inc. (London), Ltd., London.

22. Mannheim, W. 1984. Family III. Pasteurellaceae Pohl 1981, p. 550-552. In N. R. Krieg and J. G. Holt (ed.), Bergey's manual of systematic bacteriology, vol. 1. The Williams \& Wilkins Co., Baltimore.

23. Mannheim, W., W. Stieler, G. Wolf, and R. Zabel. 1978. Taxonomic significance of respiratory quinones and fumarate respiration in Actinobacillus and Pasteurella. Int. J. Syst. Bacteriol. 28:7-13. 
24. Mutters, R., M. Bisgaard, and S. Pohl. 1986. Taxonomic relationship of selected biogroups of Pasteurella haemolytica as revealed by DNA-DNA hybridizations. Acta Pathol. Microbiol. Scand. Sect. B 94:195-202.

25. Mutters, R., P. Ihm, W. Frederiksen, and W. Mannheim. 1985. Reclassification of the genus Pasteurella Trevisan 1887 on the basis of deoxyribonucleic acid homology, with proposal for the new species Pasteurella dagmatis, Pasteurella canis, Pasteurella stomatis, Pasteurella anatis, and Pasteurella langaa.
Int. J. Syst. Bacteriol. 35:309-322.

26. Speck, H., R. M. Kroppenstedt, and W. Mannheim. 1987. Genomic relationships and species differentiation in the genus Capnocytophaga. Zentralbl. Bakteriol. Mikrobiol. Hyg. A 266: $390-402$.

27. Stackebrandt, E., R. G. E. Murray, and H. G. Trüper. 1988. Proteobacteria classis nov., a name for the phylogenetic taxon that includes the "purple bacteria and their relatives." Int. J. Syst. Bacteriol. 38:321-325. 